\title{
EQUÍVOCO E CEgUEIRA
}

\author{
KELVIN FALCÃO KLEIN analisa o potencial produtivo do erro a \\ partir de uma discussão sobre Paul de Man, Harold Bloom e \\ Bernardo Carvalho
}

Pode ser produtivo pensar o equívoco crítico não apenas através de exemplos pontuais - recusas, reavaliações e querelas -, mas também através de uma reflexão sobre o equívoco como potencialidade, possibilidade e produtividade. Ou seja, a incorporação do equívoco e de sua realidade ao trabalho crítico e teórico, numa espécie de consciência da sombra, numa espécie de percepção prática dos pontos cegos que inevitavelmente fazem parte de todo gesto de leitura. E são os pontos cegos da leitura que ocupam Paul de Man em seu trabalho Blindness and Insight, por exemplo, no qual se ocupa teoricamente dessa inescapabilidade do equívoco. Toda iluminação leva a uma cegueira, já que todo foco de luz deve necessariamente levar a uma área de sombra. A história da literatura (e também a da crítica literária) seria o encadeamento e a acumulação desses momentos de luz e de sombra e, principalmente, a tensa convivência entre as duas esferas[1].

Paul de Man exemplificou a complexidade dessa dialética tanto em sua obra como em sua vida - e aqui faço referência à bastante conhecida polêmica envolvendo seu passado antissemita durante a Segunda Guerra Mundial. Quando entrei em contato pela primeira vez com a obra de Paul de Man, especificamente o volume Alegorias da leitura, o que chamou minha atenção de imediato foi a atmosfera descrente e desconfiada das ideias e dos argumentos, uma espécie de terreno movediço criado por de Man para impedir a identificação e manter o leitor sempre alerta, em estado de dúvida. Alguns comentaristas de Paul de Man, como Barbara Johnson, por exemplo, afirmam que a construção deliberada dessa resistência diante daquilo que está sendo enunciado é uma espécie de compensação, um trabalho contínuo de de Man tendo em vista a perspectivação crítica cada vez mais acentuada de seu passado 
“equivocado"[2]. Em certa medida, a conceituação empreendida por de Man ao longo de sua carreira estaria direta e irremediavelmente ligada a esse trauma inicial, um trauma ainda mais intenso por ter sido absorvido a posteriori - pois é evidente que, enquanto escrevia suas resenhas literárias no jornal colaboracionista Le Soir, de Man não tinha consciência da repercussão futura que tanto ele quanto suas ideias alcançariam. Nenhuma vida sem exame é digna de ser vivida.

Uma reflexão conceitual mais ampla sobre o tema do equívoco crítico, portanto, não pode abrir mão de um mapeamento dessas cenas traumáticas específicas, pontuais. Tal é o caso de Paul de Man, mas também poderia ser o de Ezra Pound, Louis-Ferdinand Céline, Pierre Drieu La Rochelle ou Lucien Rebatet. No caso desses escritores, a leitura de suas obras envolverá sempre uma consideração (mesmo que inconsciente ou involuntária) complementar que diz respeito aos seus posicionamentos políticos - posicionamentos que podem ou não ser tomados como equívocos. Não há posição fixa ou segura nesse contexto, pois o equívoco crítico pode se anunciar tanto na leitura exclusivamente literária ou estética dos autores em questão, quanto na leitura exclusivamente política ou ética. Os campos estão mesclados, e toda possibilidade de equívoco deve ser historicamente situada. George Steiner, ao escrever sobre a dificuldade de ler Céline, pergunta: “A criatividade estética, mesmo de primeira grandeza, pode justificar de alguma maneira a apresentação favorável da desumanidade, para nem mencionar a instigação sistemática à desumanidade? Pode uma literatura que sugere racismo, que apregoa ou faz atraente a exploração sexual infantil, merecer publicação, estudo e apreço crítico?”[3].

No que diz respeito ao difícil dilema entre o literário e o extra-literário, a posição de Harold Bloom pode ser mencionada. Isso talvez se justifique pela intensa presença de sua obra no cenário intelectual e acadêmico brasileiro, com traduções em circulação ao menos desde a década de 1990. Seu apelo se torna ainda mais direto com livros como Gênio e O cânone ocidental, que tomam uma feição bastante apreciada pelos estudantes de graduação e mesmo leigos interessados em literatura, que é a feição do manual prescritivo - uma estratégia que alcança o ápice com Como e por que ler. Para Bloom, o equívoco está justamente no excesso de 
abertura da perspectiva crítica, que redundaria, segundo ele, em um abandono do literário em prol de inúmeras reivindicações de ordem social, racial e política. Sua posição é muito clara e foi reiterada muitas vezes e em muitos livros ao longo das últimas décadas: a literatura "esteticamente forte", manejada pelo "gênio", tem a capacidade de extrapolar todo tipo de reivindicação pontual e, dessa forma, sobreviver.

O equívoco crítico, para Bloom, não diz respeito à incapacidade de abarcar múltiplos pontos de vista, mas à tendência de sobrecarregar a obra estética com pontos de vista que não são intrínsecos a ela, que não partem dela e que não são por ela requisitados. Há sem dúvida um engessamento por parte de Bloom, uma insistência na manutenção de certos preceitos críticos da Teoria Romântica, por exemplo. Eu mesmo, quando estudante, fui um leitor bastante atento de Bloom, e lembro que o ponto mais importante da experiência de leitura de seus livros foi, para mim, constatar que havia ali uma paixão, um comprometimento, um real envolvimento do sujeito que estava por trás daquelas escolhas estéticas. Por mais raivoso e preconceituoso que Bloom pudesse se mostrar, era possível estabelecer uma sorte de identificação com esse desejo de leitura onívora que ele tão bem consegue passar. O problema é que a frase pode muito bem ser reformulada: mesmo na evidência do desejo de leitura, a raiva e o preconceito ainda são bastante evidentes. Até que ponto essa problematização posterior das ideias de Bloom influencia na minha memória como leitor? Até que ponto minha atividade como crítico literário deve dar conta seja da experiência do desejo de leitura, seja da experiência da raiva e do preconceito?

É curioso que sejam os elementos externos à argumentação crítica aqueles envolvidos em boa parte dos movimentos de recusa da obra e da figura de Bloom - uma espécie de irônica vingança em direção àquele que defende justamente a pureza estética do literário. Nesse cenário de divergência, falta a maleabilidade do equívoco e sobra a rigorosidade da dicotomia que se resolve em certo e errado. Isso porque a ideia de equívoco, ao ser processada como procedimento crítico, pode dissolver em parte o idealismo estético defendido por Bloom, que postula uma forma superior que sobrevive à história. No movimento crítico que ficou conhecido como a Estética da Recepção, especialmente na apropriação 
feita por Hans Ulrich Gumbrecht das ideias pioneiras de Hans Robert Jauss, o cenário em questão fica um pouco mais arejado: "a verdadeira inovação da estética da recepção consistiu em ter ela abandonado a classificação da quantidade das exegeses possíveis e historicamente realizadas sobre um texto, em muitas interpretações 'falsas' e uma 'correta'. Seu interesse cognitivo se desloca da tentativa de constituir uma significação procedente para o esforço de compreender a diferença das diversas exegeses de um texto"[4]. Para além do "falso" e do "verdadeiro", portanto, existe um tipo de leitura crítica que toma o equívoco como um suplemento da obra de arte, como algo que diz respeito simultaneamente ao momento de sua criação e ao momento de sua recepção.

Mas é claro que esses dois eventos, criação e recepção, são heterogêneos em suas relações recíprocas, e geram, consequentemente, equívocos de naturezas diversas. Para melhor dissecar essa heterogeneidade e essa diversidade entre criação e recepção, proponho como exemplo um ensaio de Bernardo Carvalho. A escolha não é aleatória, uma vez que o próprio Bernardo Carvalho insistiu em vários momentos na potencialidade do equívoco para sua ficção e seu estilo, mantendo a posição de que a função da arte - se existe uma - é a de frustrar expectativas. E mesmo aquele que se propõe a ler metodicamente a obra até aqui publicada de Bernardo Carvalho se vê envolvido por uma série de possibilidades divergentes: estabelecendo como ponto-chave a publicação de Nove noites, é possível encarar títulos posteriores como Mongólia e O sol se põe em São Paulo tanto como aprimoramentos quanto como redundâncias; da mesma forma, os livros anteriores a Nove noites podem ser lidos como etapas preparatórias para a realização do livro decisivo ou, pelo contrário, uma série de esboços independentes e que não apresentam a coesão ou a ideia de conjunto que os três livros citados acima poderiam apresentar. Além disso, à complexidade da obra ficcional de Bernardo Carvalho é acrescentada também a complexidade de suas inúmeras e regulares intervenções ensaísticas, que frequentemente abordam de forma direta temas que surgem apenas incidentalmente em seus livros de ficção.

No caso do ensaio que pretendo resgatar, está em jogo uma discussão sobre o campo das artes plásticas no tempo presente, mas com repercussões argumentativas que permitem pensar também a literatura e 
a crítica literária, e que podem servir para condensar todos os fios que puxei ao longo deste texto. O ensaio de Bernardo Carvalho intitula-se "O espírito de corpo contra o espírito de porco" e foi publicado na nona edição da revista Serrote, em novembro de 2011. Nele, Carvalho comenta uma temporada que passou em Berlim e, mais especificamente, sua visita ao ateliê de Olafur Eliasson na cidade, no qual ocorrem "encontros interdisciplinares" com a presença de artistas, instrutores de meditação, fotógrafos, cientistas, estudiosos e mais uma vasta gama de curiosos e seguidores. A partir da descrição desconfiada da sessão interdisciplinar intensamente registrada e encenada -, Bernardo Carvalho vai montando uma reflexão sobre os contatos entre ironia, produtividade, individualidade e, claro, equivocidade no cenário artístico contemporâneo. Existe uma espécie de manto benevolente e comunitário envolvendo as atividades no ateliê de Eliasson, uma valorização do trabalho em equipe, da criação coletiva, da confluência de interesses e da reciprocidade sem conflitos nas relações. Um jogo que, segundo Bernardo Carvalho, poderia indicar uma domesticação dos seguidores e uma intensificação irônica e escamoteada da figura de Olafur Eliasson como figura do autor, do criador e do gênio.

"Todas as manifestações tendem a reiterar o mesmo ponto", escreve Carvalho, "a obra é o resultado (ou a transcrição) de uma ação (ou de uma não ação) coletiva. O grupo é um corpo - e o corpo coletivo é o artista. É um lugar-comum do nosso tempo"[5].É um lugar-comum do nosso tempo, escreve Bernardo Carvalho, ou seja, é um lugar seguro, de bases já demarcadas e discursos já estabelecidos, uma zona de conforto dentro da qual a possibilidade de erro é minimizada, dentro da qual a possibilidade do equívoco é cercada, esvaziada e inutilizada. Bernardo Carvalho apresenta em seu ensaio um diagnóstico: o coletivo e o comunitário transformaram-se em discurso comum, em moeda corrente na esfera da arte, banalizando seu instrumental e a amplitude de seus esforços. A gramática do coletivo, por conta da circulação e adesão massivas, torna-se, portanto, previsível. Mas essa previsibilidade torna o cenário ainda mais complexo, pois, ao mesmo tempo em que garante certa aprovação compulsória em sua circulação mundial, sobretudo no que diz respeito ao público interessado exclusivamente na recepção da obra de arte e não em sua criação, garante também uma entrada bastante 
desconfortável no jogo da equivocidade da crítica.

Eis como esse jogo se dá na prática, na percepção de Bernardo Carvalho: o artista "precisa da troca, da companhia, da presença dos outros, embora termine por criar um trabalho que é absolutamente autoral e individual. Por isso, precisa convencer seus colaboradores de que só há arte coletiva. Não foi à toa que o modelo do artista romântico se tornou o bode expiatório, o inimigo número um, o demônio e o mal, a imagem do anacronismo, e talvez por isso mesmo volte em breve a adquirir algum valor subversivo"[6]. De alguma forma que não deixa de ser “equivocada”, penso que seja possível, mesmo que superficialmente, unir as perspectivas de Harold Bloom e Bernardo Carvalho - e talvez do absurdo desse contato extrair alguma lição crítica. Isso é possível pela menção ao "modelo do artista romântico", o artista individual com plena posse de seu gênio, que para Harold Bloom é uma realidade constante e supra-histórica, e que para Bernardo Carvalho pode surgir como uma possível figura de vanguarda num futuro próximo. Essa irônica confluência de termos me parece bastante representativa de uma postura crítica que leve o equívoco em consideração e que passa a trabalhar em torno dele, elaborando suas possibilidades de intervenção sobre a história. Porque se o equívoco diz respeito à mobilidade conceitual, dirá respeito também a uma história, a um passado e a um arquivo que estão todos abertos, disponíveis à intervenção.

Retomando a ideia da cegueira e do insight, é possível dizer que tanto Bloom quanto Carvalho veem o mesmo fenômeno, mas dele retiram conclusões completamente diversas. Se para Bloom o gênio romântico é a representação de uma persistência ideal, de algo que diz respeito à completa ultrapassagem das etapas históricas e à manutenção de uma realização artística plena e perfeita, para Carvalho essa ideia surge como desvio e perversão do estabelecido, que terá validade artística somente até o início de sua pacificação - exatamente como aconteceu com a "arte como coletividade". Para Bloom, trata-se do gênio como um fluxo contínuo, como um processo de larga escala independente das contingências históricas, que é percebido apenas por poucos leitores privilegiados e altamente treinados. Para Carvalho, por outro lado, a figura do criador individual serve como elemento subversivo, como 
categoria operatória a ser reivindicada criticamente, a ser utilizada em sua irrupção violenta diante de um estado de coisas pego de surpresa interessa mais a impetuosidade e a monstruosidade do gênio, e não sua constituição clássica, sua monumentalização, sua fetichização.

Como uma mesma imagem do pensamento pode surgir de forma mais ou menos contemporânea e, ainda assim, tão divergente em sua interpretação? O que está em jogo aqui é aquilo que George Kubler chama de a forma do tempo, the shape of time, conceito que permite a Kubler uma análise mais precisa dos elementos artísticos que, mesmo ocorrendo de forma simultânea historicamente, dizem respeito a temporalidades completamente diversas. Em sua reflexão sobre as "séries simultâneas", Kubler realiza, mesmo que indiretamente, uma defesa do equívoco produtivo ou, ao menos, um esclarecimento acerca do uso contínuo do equívoco dentro da história das artes. Eventos simultâneos podem ter "idades sistemáticas" completamente diversas, afirma Kubler, pois nem passado nem presente são tecidos homogêneos [7]. O risco aqui é tanto negativo quanto positivo, pois existe a possibilidade, no ato de leitura crítica, de utilização de critérios formulados por uma idade em direção a obras artísticas desenvolvidas no âmbito de outra idade, distinta e heterogênea; e esse descompasso, por fim, pode levar tanto ao insight quanto à cegueira - daí a construção contingente de todo percurso crítico.

A heterogeneidade da temporalidade envolvida na formação dos artefatos artísticos, no entanto, não impede o contato entre eles, muito pelo contrário: é justamente na inevitabilidade desse contato que se funda a possibilidade de leitura, de crítica e de interpretação. O próprio Kubler aponta isso, vinte anos depois da publicação de seu livro, afirmando que dois grupos muito distintos se formam a partir da leitura de The shape of time, aqueles que não entendem "uma única palavra" e aqueles que entendem tudo, "sem dificuldade", "já na primeira leitura". Mas, ainda segundo Kubler, a distinção entre os dois grupos não se dá no contato com suas palavras e suas reflexões, e sim a partir das concepções prévias dos dois grupos no que diz respeito às obras de arte - ou seja, ao sistema avaliativo que antecede a leitura e que forma a percepção dos críticos[8]. Para Kubler, a validade de seu livro e de suas ideias reside 
nesse intervalo de controvérsia e contradição, nesse espaço aberto ao equívoco e a sua mobilidade. Não só seu livro e suas ideias, eu acrescentaria, mas boa parte dos esforços da crítica e da teoria.

[1] DE MAN, Paul. Blindness and insight: essays in the rhetoric of contemporary criticism. Nova York: Oxford University Press, 1971.

[2] JOHNSON, Barbara. The wake of deconstruction. Oxford: Blackwell, 1994.

[3] STEINER, George. "Homem gato". In: Tigres no espelho: e outros textos da revista The New Yorker. Tradução de Denise Bottmann. São Paulo: Globo, 2012, p. 253.

[4] GUMBRECHT, Hans Ulrich. "Sobre os interesses cognitivos, terminologia básica e métodos de uma ciência da literatura fundada na teoria da ação". In: JAUSS, Hans Robert et. al. A literatura e o leitor. Textos de estética da recepção. Organização e tradução de Luiz Costa Lima. Rio de Janeiro: Paz e Terra, 1979, p. 191.

[5] CARVALHO, Bernardo. "O espírito de corpo contra o espírito de porco". São Paulo, Instituto Moreira Salles, Serrote, n. 9, novembro de 2011, p. 81.

[6] Ibidem. p. 80.

[7] KUBLER, George. The shape of time. New Haven: Yale University Press, 1972.

[8] Idem. "The shape of time. Reconsidered". Perspecta, v. 19, (1982), pp. 112-121, Yale University, School of Architecture (a citação está na página 112).

\footnotetext{
KELVIN FALCÃO KLEIN é doutor em Teoria Literária pela UFSC e autor de Conversas apócrifas com Enrique Vila-Matas (Modelo de Nuvem, 2011). É responsável pelo blog Um túnel no fim da luz 